1 Universidade Federal de São Carlos (UFSCar) - São Carlos (SP), Brasil. fernandafeliciolima@gmail. com

2 Universidade Federal do Rio Grande do Norte (UFRN) - Natal (RN), Brasil.

\section{Percepções e experiências de mulheres atuantes no campo da saúde sobre violências de gênero}

\author{
Perceptions and experiences of women active in the health field on \\ gender violence
}

Fernanda Felício de Lima', Sabrina Helena Ferigato', Carla Regina Silva', Ana Luiza de Oliveira e Oliveira ${ }^{2}$

DOI: $10.1590 / 0103-1104202213205$

RESUMO Este artigo é fruto de uma pesquisa de mestrado que se propôs a mapear e analisar as percepções de mulheres que atuam no campo da saúde coletiva brasileira sobre violências de gênero vividas e expressas em seus cotidianos, a partir do recorte de um estudo amplo, intitulado 'Mulheres da Saúde Coletiva: um retrato de quem constrói o campo', desenvolvido pelo movimento de pesquisa-intervenção-luta de mulheres atuantes nesse campo, que formam a ‘Coletiva Adelaides: Feminismos e Saúde'. Trata-se de um estudo quanti-qualitativo, do tipo pesquisa-intervenção, que parte do método da cartografia e dos referenciais teóricos das epistemologias feministas negras. Os resultados são apresentados com base na tipificação das violências percebidas pelas mulheres, na sua interface com o processo do trabalho em saúde e na cotidianidade, apontando para a persistência e a gravidade das violências identificadas no cotidiano de mulheres atuantes no campo da saúde coletiva e nas contribuições possíveis para os estudos de gênero, que se dão pelo aprofundamento e pela análise desse cenário a partir da articulação dos conceitos de interseccionalidade e política do empoderamento, bem como pelo delineamento de possibilidades para enfrentamento dessas violências.

PALAVRAS-CHAVE Violência de gênero. Estudos de gênero. Feminismo. Interseccionalidade. Saúde pública.

ABSTRACT This article is the result of a master's research that aimed to map and analyze the perceptions of women who work in the field of Brazilian public health on gender violence experienced and expressed in their daily lives, through the cut-out of a broad study, entitled 'Women of Collective Health: a portrait of who builds the field', developed by the research-intervention-struggle movement of women active in this field, who form the 'Collective Adelaides: Feminisms and Health'. This is a quanti-qualitative study, intervention-type research, which starts from the mapping method and the theoretical references of black feminist epistemologies. The results are presented based on the typification of violence perceived by women, their interface with the process of work in health and daily life, pointing to the persistence and severity of the violence identified in the daily life of women working in the field of collective health and the possible contributions to gender studies, which are given by the deepening and analysis of this scenario from the articulation of the concepts of intersectionality and empowerment policy, as well as the delineation of possibilities for coping with these violence.

KEYWORDS Gender-based violence. Gender studies. Feminism. Intersectionality. Public health. 


\section{Introdução}

Histórica e culturalmente, observa-se em todas as sociedades modernas, em menor ou maior grau, a influência do sistema patriarcal nas organizações sociais e relações de gênero que, por consequência, estabeleceram-se a partir da dominação e do controle do homem sobre a mulher e que promovem a violência masculina contra as mulheres1-3. Em uma cultura machista, "[...] a violência é o meio mais eficaz para coagir e subordinar a parceira à vontade masculina $\mathrm{e}$ de fazê-la obedecer às regras do homem"4(254).

Nos espaços privados, a violência de gênero, caracterizada como violência doméstica ${ }^{5}$, no geral, é exercida por homens que têm laços de parentesco, consanguíneos ou de afinidade com as mulheres vitimadas ${ }^{2}$.

Embora haja leis que caracterizam os diferentes tipos de violência sofrida por mulheres em âmbito doméstico e familiar e/ou público e a promulgação de uma lei que caracteriza o desdobramento fatal da perpetuação da violência de gênero contra mulheres, os índices apontam o Brasil como o $5^{\circ}$ (quinto) país com a maior taxa de homicídios de mulheres no mundo ${ }^{6-8}$.

De acordo com o 'Mapa da Violência 2015: homicídio de mulheres no Brasil'7, entre os anos de 2003 e 2013, o homicídio de mulheres brancas teve uma queda de $9,8 \%$, enquanto o homicídio de mulheres negras teve um aumento de $54,2 \%$. Em consonância com esses dados, o 'Atlas da Violência'8 demonstra que houve crescimento nos índices de homicídio de mulheres, indicando o assassinato de 13 mulheres por dia no país, totalizando, em 2017, o número de 4.936 mulheres mortas por assassinato.

Evidencia-se a importância de análises interseccionais quanto aos marcadores sociais, a fim de compreender a complexidade que permeia os processos de violências contra as mulheres, visto que todas estão sujeitas a vivenciar discriminações de gênero. Assim, os fatores relacionados a identidades e lugares sociais (raça, cor e etnia; classe; religião; orientação sexual; entre outros) ocupados por determinados grupos de mulheres podem ser tomados como categorias analíticas para desvelar e modificar tais experiências opressivas.

Esse panorama é permeado pela inseparabilidade de cultura e política e se constitui como possível estratégia para responder às questões socioeconômicas e de vulnerabilidades para além do processo saúde-doença que historicamente tem pautado as práticas de cuidado, numa tendência atual de medicalização da vida9 e, em parte, de controle da vida.

Considerando-se a gravidade do problema e as medidas mínimas ou insatisfatórias promovidas pelo Estado ${ }^{\mathbf{1 0}, 11}$, ressalta-se a importância da atuação de entidades não governamentais e dos movimentos e organizações feministas brasilei$\operatorname{ros}^{12}$ como atores políticos e sua capacidade de impulsionar políticas públicas de efetivação da cidadania das mulheres, em especial, no que se refere ao enfrentamento das violências de gênero.

Nesse sentido, esta pesquisa se desenvolveu com base em um recorte da produção científica nacional de um grupo de mulheres brasileiras profissionais de saúde de diferentes áreas técnicas e regiões do País que atuam no campo da saúde coletiva e se organizaram enquanto grupo feminista 'Coletiva Adelaides: Feminismos e Saúde', a fim de promover ações de tensionamento e construção de movimento político, afetivo e científico para produção de conhecimento situado por meio dos feminismos, em defesa do cuidado, da vida e, sobretudo, das mulheres ${ }^{\mathbf{1 3}}$.

A Coletiva Adelaides é composta majoritariamente por mulheres brancas e constituída por grupos de diferentes correntes dos feminismos. A autora principal deste artigo é negra, e este é derivado de sua dissertação de mestrado, que foi construída com o intuito crítico de lançar luz a esse cenário a partir da perspectiva dos estudos de gênero, especificamente, do feminismo negro, sendo delineada por mulheres de diferentes raças/etnias que participam da Coletiva e atuam no campo da saúde coletiva.

O objetivo deste estudo, que se debruça sobre os dados produzidos resultantes da pesquisa mais ampla, foi mapear e analisar as percepções e experiências de mulheres que atuam no campo da saúde no Brasil sobre 
violências de gênero, vividas e expressas em seus cotidianos. Como referenciais teórico-metodológicos tomamos a cartografia, bem como as epistemologias feministas negras para a análise temática dos dados.

Para embasar a discussão desses dados, partir-se-á do conceito da interseccionalidade 14-18 (que se dispõe a analisar e pensar articuladamente raça, gênero e classe social interceptadas em uma matriz de opressões sobrepostas) e da política do empoderamento ${ }^{19}$ (compreendida como política de potencialização, autoafirmação, autovalorização, autorreconhecimento/conhecimento de si e de sua história para a análise crítica e afirmação de sua posição coletiva, social e política).

\section{Percurso e métodos}

A interface entre saúde e violência de gênero pode ser identificada quando se pensa a função do sistema de saúde e de seus profissionais na assistência às vítimas de violência, assim como nas estratégias setoriais de enfrentamento da cultura de violência como um determinante do processo saúde-doença-intervenção. No entanto, uma das facetas dessa interface, ainda pouco explorada pelos estudos em saúde, é a expressão da violência de gênero por dentro do sistema de saúde.

Ou seja, no campo da saúde, devido à divisão sexual do trabalho, aos impactos do patriarcado e ao sexismo ${ }^{\mathbf{1}, 6,10,13}$, as mulheres são situadas como centrais nas relações de cuidado. Nessa direção, dois problemas podem ser identificados: o cuidado como prática doméstica e a decupagem desse papel em seu ambiente de trabalho. Então, quando posicionadas como cuidadoras dentro de um sistema de saúde, a relação público e privado se materializa nas relações de trabalho e de atenção à saúde de modo a excluir suas trajetórias de vida - que são afetadas no exercício relacional desse cuidado, em condições e contextos diversos, a depender de outros marcadores sociais como sua posição de classe e restrições determinantes do racismo estrutural e institucional'.

Composto por um grande contingente de mulheres cuidadoras profissionais, o campo da saúde não está imune de ser um espaço de reprodução das violências estruturais da sociedade patriarcal, tampouco coloca essas mulheres em um lugar blindado das violências que elas próprias buscam enfrentar a partir dos recursos técnico-afetivos disponíveis em seus contextos profissionais.

Tendo em vista essas considerações, a Coletiva Adelaides propôs uma pesquisa ampliada, aprovada pelo Comitê de Ética de Pesquisas com Seres Humanos pela Universidade Estadual de Campinas ( ${ }^{\circ}$ 063486/2018) ${ }^{20}$, que abrangeu mulheres trabalhadoras, gestoras, pesquisadoras e ativistas da saúde coletiva de todo o Brasil e retratou, em uma perspectiva de gênero, quem são as mulheres atuantes na construção desse campo, quais são suas trajetórias e ao seus modos de atuação/intervenção.

Para tanto, a Coletiva Adelaides desenvolveu e validou um instrumento de coleta de dados, isto é, um questionário autoaplicável e autogestionado ${ }^{20}$ que esteve hospedado on-line na plataforma Google ${ }^{\circledR}$ Forms por um período de oito meses (de julho de 2018 a fevereiro de 2019), a fim de garantir livre acesso e fácil manuseio de todas as respondentes do questionário, ou seja, mulheres trabalhadoras, gestoras, pesquisadoras e ativistas do campo da saúde coletiva, de todas as regiões do País. O referido questionário conta com cinco eixos norteadores: Dados gerais sobre o acesso aos direitos sociais básicos; A atuação profissional/ acadêmica na saúde coletiva; Engajamento social e o ativismo político; Experiências envolvendo machismo e violência; Aspectos da maternidade (para quem tem filhos/as/es).

Nesses eixos estão inseridas 12 seções (quadro 1), com questões obrigatórias e opcionais, que variam entre perguntas fechadas (múltipla escolha) e abertas (possibilidade de desenvolver comentários e narrativas a fim de aprofundar qualitativamente determinados eixos). 


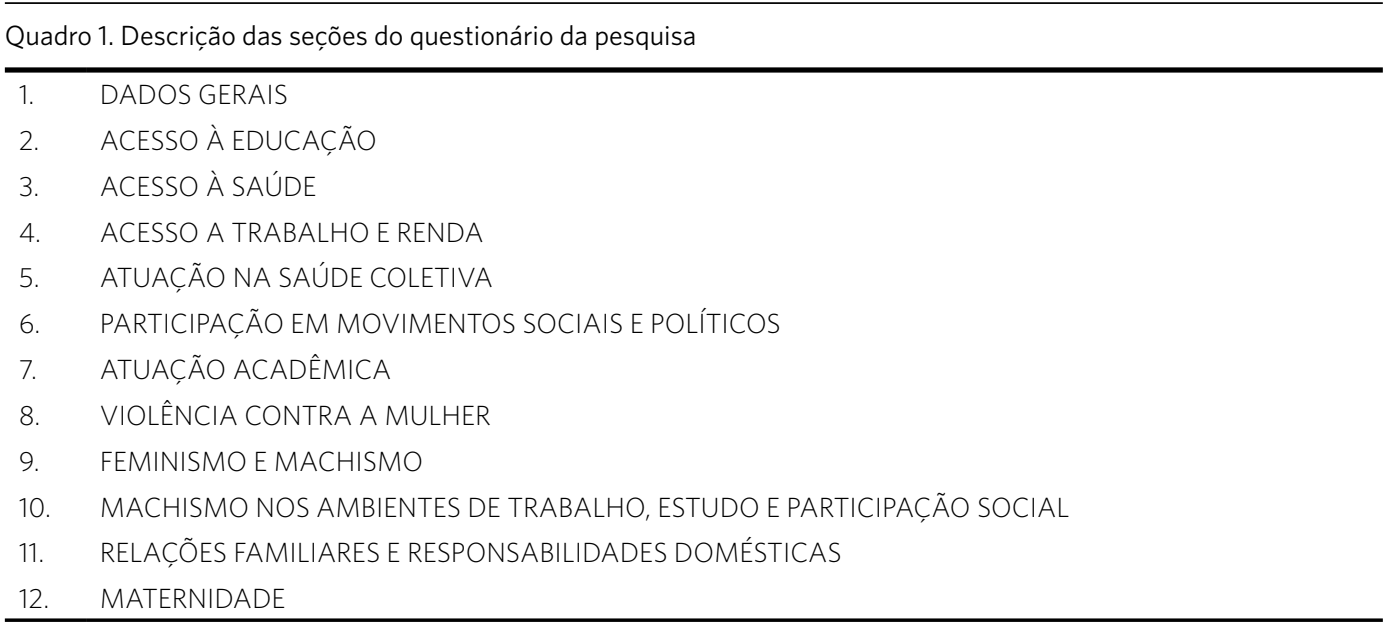

Fonte: Elaboração própria.

A seleção de participantes foi feita a partir do recrutamento em snowball, isto é, por meio da técnica de amostragem por bola de neve21, na qual a Coletiva Adelaides atuou como semente. O local de divulgação do questionário se deu pelos espaços on-line (redes sociais e aplicativo multiplataforma de mensagens instantâneas e comunicação em áudio e vídeo), nos quais cada respondente enviava o questionário para outras mulheres e/ou grupo de mulheres aos quais estava vinculada, tendo como critérios de inclusão:

- Ter acesso à internet e a redes sociais;

- Ser mulher (cisgênero, travesti ou transsexual) que se autorreconhece como profissional, trabalhadora, pesquisadora ou ativista no campo da saúde coletiva;

- Responder com aceite o Termo de Consentimento Livre e Esclarecido (TCLE) para participação voluntária na pesquisa.

Partindo do anseio de compreender quais são as percepções e experiências relacionadas à violência de gênero das mulheres que atuam no campo da saúde no Brasil, bem como suas produções de estratégias e tensionamentos para enfrentamento e/ou superação das violências, o estudo quanti-qualitativo que origina este artigo se desvela a partir de um recorte da pesquisa ampliada, com foco em uma cartografia do eixo das 'Experiências envolvendo machismo e violência'.

Optou-se por esse recorte pelo movimento teórico-subjetivo que produziu nas pesquisadoras durante o processo de participação como respondentes do questionário. Além do pressuposto de que existe um intercruzamento entre marcadores sociais da diferença e o exercício desigual de poder que produz lugares e acesso distintos para diferentes grupos de mulheres e contribui para o aumento e a persistência cotidiana das violências praticadas contra elas.

A escolha da cartografia como método para análise dos dados se faz pela oportunidade que o método oferece para que o processo de implicação das pesquisadoras fosse considerado enquanto parte do próprio ato de pesquisar, numa ruptura explícita com a suposta neutralidade entre objeto de pesquisa e pesquisador ${ }^{22}$, por meio do acompanhamento de um processo narrado, cujo objetivo rompe com a lógica de representar um objeto, e se propõe a desenhar as conexões e os caminhos oferecidos pelo campo de pesquisa ${ }^{23}$.

Embora as autoras deste estudo não estivessem inseridas em um campo empírico específico, entende-se que os processos narrados, ainda que, aparentemente, explicitando vivências passadas, presentificam-se em todas as mulheres inseridas no campo da saúde. Desse modo, partindo de um universo de dados já produzidos, propõe-se experimentá-los e analisá-los por meio do 
encontro com os índices percentuais das violências sofridas e com as narrativas das mulheres participantes da pesquisa ampliada.

Consideram-se para este artigo as respostas oriundas das questões semiestruturadas dos eixos selecionados, bem como as narrativas produzidas pelas mulheres no campo para comentários livres, inscrito no eixo 'Violência Contra a Mulher'. Ressalta-se que não houve qualquer definição prévia no questionário quanto a esses conceitos, de modo que as respostas produzidas se pautam necessariamente na definição e interpretação singular e subjetiva de cada uma das mulheres para essas categorias.

As narrativas foram lidas integralmente e, depois, distribuídas em 12 categorias temáticas, de acordo com o quadro 2. Essa etapa, densa e, ao mesmo tempo, delicada por sua complexidade, foi permeada por reflexões envolvidas na escolha de quais narrativas devem ser elencadas e como devem ser apresentadas. Para tanto, os fundamentos da cartografia atuaram como fio condutor da discussão, alinhada ao compromisso de não produzir reducionismos sobre a importância e a singularidade das histórias partilhadas.

Optou-se por manter as narrativas em sua totalidade, respeitando as escolhas descritivas das mulheres participantes, suprimindo apenas trechos que poderiam comprometer a preservação ética da identidade dessas mulheres. Além disso, foram editadas palavras abreviadas e/ou compreendidas como erros de digitação, sem qualquer prejuízo ou alteração de seu significado.

Em uma análise interseccional15,18, procurou-se visibilizar essas questões, assim como as lutas, os enfrentamentos e as resistências das mulheres participantes e de que maneira outras intersecções (como o racismo, o sexismo, a desigualdade de classe, a heteronormatividade, entre outras opressões e relações de poder) são produzidas e se apresentam no cotidiano. Partiu-se da compreensão de que as opressões e os marcadores sociais se intercruzam e trabalham juntos para produzir e fazer perpetuar um conjunto de injustiças sociais no plano coletivo que podem contribuir para o surgimento do sentimento de impotência subjetiva no plano individual.

\section{Resultados e discussão}

O questionário foi respondido por 1018 mulheres, tendo sido desenvolvido o seguinte retrato sociodemográfico: são mulheres inseridas em 23 estados do território nacional, nascidas entre os anos de 1941 e 1999. Há maior predominância de mulheres participantes na região Sudeste (44,6\%), seguida por Nordeste $(25,4 \%)$, Sul (20,3\%), Centro-Oeste (5,9\%) e, por último, Norte $(3,8 \%)$.

Sobre identidade de gênero, 994 mulheres (97,6\%) se declaram cisgênero (se identificam com gênero de nascença); quatro (0,4\%) são transgênero (não se identificam com gênero de nascença); as demais (menos de $3 \%$ ) se caracterizam como cis não satisfeita com o papel social atribuído ao gênero; não binárias; femininas; do sexo feminino; bissexuais ou heterossexuais, panorama que evidencia a diversidade quanto às definições e compreensão sobre diferenças entre as categorias identidade de gênero e orientação sexual.

Quanto à orientação sexual, 874 se declaram heterossexuais ( $85,9 \%)$; 105 bissexuais (10,35\%); 36 homossexuais (3,5\%); uma pansexual; uma lésbica e uma que declara gostar de pessoas e não de classificá-las.

Em conformidade com esses dados, ressalta-se a necessidade e aimportância do aprofundamento de estudos qualitativos e quantitativos sobre essa temática, a fim de abarcar a potência de tamanha diversidade e pautar as pesquisas, de modo a incluir as diferentes categorias identitárias e de sexualidade que compõem o universo relacional para além dos padrões cisheteronormativos.

Na caracterização quanto ao estado civil, 371 são solteiras ou separadas judicialmente (36,4\%); 350 casadas (34,4\%); 222 em união estável (21,8\%); 63 divorciadas (6,2\%); e 12 viúvas (1,2\%). Destaca-se, com relação a esse panorama, que a maioria das mulheres participantes acessa algum tipo específico de arranjo familiar (572 mulheres, considerando as casadas ou em união estável), que, possivelmente, pode produzir divisão de tarefas e papéis sociais, mesmo que desiguais, devido ao patriarcado e ao sexismo. 
Sobre maternidade, a fim de identificar mulheres que sofreram violências obstétricas, considerou-se pertinente a análise de que 472 (46,4\%) das 1018 respondentes engravidaram em algum momento de suas vidas; 251 (24,6\%) mulheres sofreram aborto; enquanto 295 (29\%) não vivenciaram processos gestacionais.

Para caracterização racial e étnica, as participantes tiveram autonomia para definir como se declaram, a partir de opções estabelecidas pelo questionário, além de um campo livre para comentários descritivos, denominado 'Outra'.

Tendo em vista a diversidade do panorama étnico-racial produzido, para fins de comparabilidade com outras pesquisas e para identificar os diferentes processos de autodeclaração de raça/ etnia, esta pesquisa se pautou na distribuição classificatória proposta pelo Instituto Brasileiro de Geografia e Estatística (IBGE), bem como nas discussões políticas que apontam a divisão entre pardos e pretos como um dos efeitos do projeto colonialista de embranquecimento da população ${ }^{\mathbf{2 4}}$. Para Gonzalez ${ }^{\mathbf{1 8}}$, a ideologia do branqueamento é uma das bases que amparam os discursos de construção de uma suposta 'democracia racial' expressa pelos processos de miscigenação.

Sendo assim, para análise dos dados da pesquisa, considerou-se a apresentação dos resultados nas categorias 'Mulheres Brancas' e 'Mulheres de Cor'15, a saber, negras, amarelas e indígenas, além de outras nomenclaturas da categoria 'Outra', como multicolorida; brasileira misturada; sem enquadramento formal; misturada como as brasileiras de forma geral. O termo 'mulheres de cor' adotado remete à compreensão que Akotirene ${ }^{15}$ apresenta na nota 6 da obra Interseccionalidade:

Na epistemologia feminista negra adotamos uma política de tradução que respeita os significados políticos originais, neste caso 'mulheres de cor' contém mais representatividade que 'mulheres não-brancas'.

Especificamente para a produção deste artigo, as análises comparativas, a partir deste ponto, serão desenvolvidas a partir do agrupamento de mulheres brancas (685) e mulheres negras
(304), a saber, as mulheres que se declararam como pretas; pardas; afrodescendentes; morenas; nem brancas nem pretas.

Numa análise comparativa entre as mulheres negras, as mulheres brancas e os processos de relacionamentos, observa-se que $30 \%$ (90) delas afirmam não ter um relacionamento, comparadas aos $16 \%$ (111) de mulheres brancas que também não estão em um relacionamento, ou seja, havia o dobro de mulheres negras que afirmaram não estar em um relacionamento, quando comparadas às mulheres brancas.

É possível apreender, também, a existência hegemônica, a partir desses arranjos familiares, de um modelo socialmente aceito do que tem sido considerado como rede de apoio e suporte. Condição que corrobora os estudos que apontam para maior vulnerabilidade com relação às redes de apoio e suporte de mulheres que estão fora dos padrões eurocêntricos de raça e etnia (mulheres amarelas, indígenas, negras, entre outras), que não se alocam em grupos relacionais cisheteronormativos, bem como mulheres pobres e/ ou periféricas com menor acesso à educação e a trabalhos formais $\mathbf{1 , 7 , 8 , 1 8}$.

No eixo de Acesso à Educação, há uma paridade entre o acesso à educação fundamental e ao ensino médio: 50,5\% estudaram em escolas públicas (514 mulheres) e 49,5\% em escolas privadas (504 mulheres). Entretanto, entre mulheres brancas (685) e mulheres negras (304), os índices demonstram que 568 das brancas cursaram escola pública, comparadas às 267 negras, ou seja, $88 \%$ das mulheres negras estudaram exclusivamente em escolas públicas.

Com relação à pós-graduação, observa-se que $50 \%$ das brancas (339) concluíram a pós-graduação em Instituições Públicas, comparadas às 124 negras (41\%). Quanto aos cursos de pós-graduação, as mulheres brancas também possuem percentuais melhores: $12 \%$ cursaram Doutorado (80); 31\% Mestrado (210); 46\% Especialização (317); e 22\% Residência (153), comparadas às mulheres negras, entre as quais, $8 \%$ cursaram Doutorado (24); $27 \%$ Mestrado (81); 37\% Especialização (112); e 21\% Residência (64). 
Quanto ao item referente a Acesso a Trabalho e Renda, observa-se que $54 \%$ das mulheres brancas estão trabalhando (366), em comparação às $42 \%$ das negras (129). $33 \%$ das brancas (228) e $40 \%$ das negras (123) trabalham e estudam. $21 \%$ das mulheres brancas (142) têm maior acesso a renda (de 3 a 5 salários-mínimos - entre $\mathrm{R} \$ 2.862,00$ e $\mathrm{R} \$ 4.770,00)$, enquanto, para as mulheres negras, a porcentagem é de $25 \%$ (75).

Este retrato das mulheres atuantes na saúde coletiva e que foram participantes desta pesquisa demonstra um universo específico de mulheres que acessam maiores e melhores condições de suporte e participação social, dado o conjunto de marcadores sociais que as caracterizam em lugar social privilegiado: maioria branca; com acesso a muitos anos de educação; a trabalho e renda, portanto, com maior poder concreto e simbólico. Mas que, ainda assim, são vulnerabilizadas pelas violências impostas pelas opressões de gênero.

\section{Percepções e narrativas sobre violência contra a mulher}

No eixo 'Violência Contra a Mulher', 1.004 mulheres responderam às questões sobre sua percepção quanto à violência contra a mulher, das quais, apenas 183 (18\%) afirmam não terem sido vítimas de violência por serem mulheres.

As perguntas possibilitaram que mais de uma opção de resposta fosse assinalada, de maneira que há especificidades quanto aos tipos de violências de gênero que 821 (82\%) mulheres declaram ter sofrido e ao modo como identificam que essas violências e discriminações se expressam em seu cotidiano. Novamente, no comparativo entre mulheres brancas e mulheres negras, observam-se maiores índices de violências entre as mulheres negras.

A partir das questões abertas, solicitou-se que as mulheres participantes narrassem livremente em maior profundidade suas vivências quanto à violência contra a mulher, por meio da sentença disparadora 'Queremos saber mais sobre as suas vivências e percepções sobre a violência. Comente sua resposta anterior, se desejar'. Foram produzidas 254 respostas.
Compreende-se que existe uma diversidade de experiências e modos de ser mulher, que se estabelecem a partir dos lugares sociais que ocupam e que são condicionantes ao acesso (ou não) de oportunidades para exercício pleno de sua cidadania, enquanto sujeitos de direitos. Nesse sentido, é necessário romper com uma visão universal (do homem branco, colonizador, cisheterossexual) das vivências e experiências de mulheres, considerando

[...] as categorias de raça, gênero, classe e sexualidade como elementos da estrutura social que emergem como dispositivos fundamentais que favorecem as desigualdades e criam grupos ${ }^{17(61)}$.

Com base nisso, apresenta-se o panorama a seguir (quadro 2), organizado a partir do modo como as violências são tipificadas no Brasil, isto é, baseado na Lei Maria da Penha (11.340/2006) e contendo alguns trechos de narrativas que foram adicionadas para este artigo.

É preciso, para uma análise crítica dos dados apresentados, contextualizar as violências tipificadas tendo como critério as interviolações (violências que acontecem em diferentes esferas de suas vidas e se relacionam entre si) sofridas pelas mulheres e que são interseccionais, como foi identificado a partir dos dados comparativos entre mulheres brancas e mulheres negras (pretas; pardas; afrodescendentes; morenas; nem brancas nem pretas), assim como mulheres LGBTI+ (não pertencentes e/ou que não se identificam com padrão cisheteronormativo). Destacam-se, também, especificidades de violência para mulheres que experienciaram processos gestacionais (engravidaram e/ou sofreram aborto).

Nesses casos, os índices de violências se alteram e se estratificam a partir das opressões interseccionais, ou seja, embora o número de participantes respondentes inseridas nesses grupos seja significativamente menor, os índices de interviolações vividas abrangem uma porcentagem muito acima da média, se comparados com grupos de mulheres definidos por outros marcadores sociais, como indicado no quadro 2. 
Quadro 2. Caracterização contextualizada e expressão das violências de gênero

\begin{tabular}{|c|c|c|c|}
\hline $\begin{array}{l}\text { Índice numérico } \\
\text { contextualizado }\end{array}$ & Violências tipificadas & $\begin{array}{l}\text { № de mulheres } \\
\text { que sofreram as } \\
\text { violências }\end{array}$ & Narrativas produzidas \\
\hline 1 & Violência Psicológica & $437(42,9 \%)$ & $\begin{array}{l}\text { Recebi comentários de um professor sobre atuar na área cirúrgica e ser mãe, afirman- } \\
\text { do que não há como ser as duas coisas. Sobre a violência psicológica, sofri pressão } \\
\text { psicológica do meu pai durante } 19 \text { anos por defender a minha mãe, e ele não aceitar a } \\
\text { sua autonomia por ser mulher. }\end{array}$ \\
\hline 2 & $\begin{array}{l}\text { Discriminação por } \\
\text { ser Mulher }\end{array}$ & $435(42,7 \%)$ & $\begin{array}{l}\text { É muito difícil ser mulher nesse mundo. Andar pelas ruas é, por si, um grande risco. } \\
{[\ldots . .] \text { Atuar na política sendo mulher é }[\ldots . .] \text { um grande desafio. [...] boa parte das vezes }} \\
\text { que fui chefiada por homens tive minha fala tolhida, meu comportamento questiona- } \\
\text { do, minhas ideias subjugadas. }\end{array}$ \\
\hline 3 & Violência Moral & $315(30,9 \%)$ & $\begin{array}{l}\text { [...] vítima de perseguição sexista e assédio moral no trabalho e tive que abandonar } \\
\text { meu cargo de diretora de um departamento, pois eram cinco diretores homens e so- } \\
\text { mente eu de mulher. Minhas opiniões eram constantemente desconsideradas e minha } \\
\text { autoridade ignorada! Não suportei tanta pressão e saí do cargo! }\end{array}$ \\
\hline 4 & $\begin{array}{l}\text { LGBTIFOBIA } \\
\text { (Mulheres que não } \\
\text { estão/se identificam }\end{array}$ & $50(29,8 \%)$ & $\begin{array}{l}\text { [...] Nunca sofri a violência física, mas tenho medo de andar na rua, de ser atropelada } \\
\text { ao andar de mãos dadas com minha namorada, de ocupar espaços públicos e ser } \\
\text { deslegitimada. }\end{array}$ \\
\hline
\end{tabular}

Conduta médica culpabilizadora e terapêutica punitiva (sem analgésicos, longas horas de espera) em dois hospitais por tentativa de aborto [...]

Levei um tapa na cara de um policial, pois não deixei ele revistar meu corpo.

(Mulheres que se autodeclaram de cor/ não brancas $=333$ )

[...] Já me pediram para prender meu cabelo com pente porque o colega se incomodava com as "ondinhas" que faziam meu cabelo. Fora paciente que nem conheço e recusa logo atendimento porque [...] eu nunca sou a médica da unidade, sou sempre a técnica de enfermagem ou a enfermeira. Não estou rebaixando nenhum profissional, pelo contrário, sem eles é inviável o meu serviço. Mas as pessoas ainda têm muita dificuldade de aceitar que existe, sim, uma médica mulher negra!

Na infância, já tive ao menos 5 tentativas de violência sexual: seja de estranhos na rua, que pediam informações dentro de carros e quando eu me aproximava estavam nus, desde pessoas próximas da família, que tentavam se aproximar. A violência sexual nunca se consumou em ato sexual, mas toda criança/adolescente mulher passa por esses constrangimentos! [...]

Sofri violência obstétrica [...] tentaram negar meu acesso ao parto humanizado, com a enfermeira obstétrica que atuava no serviço. Me colocaram acesso venoso e ocitocina sintética contra minha vontade, fizeram inúmeros toques desnecessários, mas, ao final, consegui parir naturalmente, graças à intervenção/defesa da enfermeira obstetra que estava de plantão.

(Mulheres que engra-
vidaram e/ou sofreram aborto $=723$ ) Vida Adulta
Me sinto como se fosse descartável, tenho medo do meu atual parceiro, tenho medo de não conseguir vencer essa guerra... tem noites em que não durmo pelo simples fato de não saber se estarei de pé no dia seguinte.

Fui vítima de um relacionamento abusivo no meu primeiro casamento. Violência física e psicológica. Demorou pouco menos de dois anos para que eu conseguisse sair do relacionamento, mas as marcas duram até hoje [...]

Vivi um relacionamento abusivo por 5 anos [...] Trabalhei com um médico que fazia diversas brincadeiras com cunho pejorativo e sexual, inclusive na frente da equipe de enfermagem. Já fui assediada sexualmente durante um assalto, acredito que só escapei do estupro porque me neguei a ir a uma rua escura com ele, mas ainda assim ele passou a mão em mim.

[...] Meus livros e coisas já foram jogados no lixo por cônjuge; que também já fingiu que me trombou, quando na verdade veio em minha direção para atacar-me (parti pra cima questionando-o, e acabou assumindo a ação).

Fonte: elaboração própria. 


\section{As tipificações das violências de gênero e sua transversalização nas zonas comuns existenciais de mulheres atuantes no campo da saúde}

Outro ponto a ser ressaltado na análise deste estudo se mostra a partir do mapeamento dos espaços da vida cotidiana nos quais se expressam as violências narradas. Nomeou-se essa interface, entre a violência e a cotidianidade, como zonas comuns de existência, que são permeadas/marcadas por violência de gênero, isto é, organizações cotidianas que se constituem a partir de processos de vida partilhados pelas mulheres, enquanto parte de um modelo geral de estrutura social e que são, também, espaços marcadamente violentos.

Foram definidas cinco zonas comuns de existência (quadro 3) nas quais observou-se predominância e persistência da violência nos relatos e experiências, tanto nos espaços de vida quanto no modo como se expressam essas agressões e violações no cotidiano das mulheres e em seus fazeres diários.

\section{A violência psicológica foi em relação ao primeiro namorado que tive na adolescência. A violência moral está junto à discriminação racial (embora eu me considere branca, já morei em lugares em que me consideravam negra e por eu ser mulher). Além disso, sofri violência pelo local em que morava, periferia [...] discriminação nos mais diversos am- bientes. Em relação à violência sexual, tive um episódio de abuso [...] um parente passou a mão em mim [...]}

Essa narrativa evidencia a violência psicológica com parceiro na adolescência e que, portanto, apresenta-se na relação afetiva partilhada; a violência moral que, junto à discriminação racial, expressa-se em diferentes espaços de circulação, entre eles, na ocupação do espaço público a partir da moradia, nesse caso, em região periférica, condição que gera como desdobramento o sentimento de não pertencimento e inferioridade, bem como a existência vulnerável.
Aqui, o racismo opera a partir de um emaranhado complexo, pois, ao mesmo tempo que uma mulher negra com uma pele mais clara (possivelmente parda) - identificação pessoal, conforme os processos históricos de miscigenação e política do embranquecimento ${ }^{\mathbf{1 8 , 2 4}}$ - tem acesso a alguns direitos que a mulher negra retinta não acessa, ela também é desprovida do direito à identidade e à autodefinição étnico-racial, pois não recebe o mesmo tratamento que uma mulher branca.

[...] Parceiro íntimo machista que insistia em me diminuir e em tentar se colocar numa posição superior. Desvalorizava meus atributos profissionais e minhas características femininas físicas e de mulher negra. Mantinha um discurso machista de que eu não tinha que discordar de sua opinião.

Observa-se que a discriminação de gênero e a violência psicológica se delineiam nas zonas comuns de relações afetivas e nos espaços domésticos, assim como a identidade racial é determinante nos processos de opressão, visto que as características e os atributos ancestrais e da negritude ${ }^{15}$ amplificam as humilhações desenvolvidas pelos parceiros. Ressalta-se que não foram levantadas informações sobre os parceiros e que seria necessário realizar distintas análises entre casais de mesmas ou distintas identidades raciais, pois há uma série de diferenças já debatidas na literatura e pelos movimentos sociais e negros que abrem diferentes perspectivas para se compreender o fenômeno da violência sofrida pela mulher negra em uma sociedade machista e racista.

As especificidades que acompanham a condição biológica de ser mulher, tal como o ato de gerar vida, podem se tornar sinônimo de discriminação e violência - refletidas na indisponibilidade de acolhimento e desrespeito às mulheres gestantes -, de acordo com as demandas ocasionadas nesse processo de vida. Essas discriminações podem se desenvolver nos processos de trabalho/estudo e, inclusive, ser reproduzidas por mulheres, como se destaca neste relato: 
[...] Tive minha opinião menosprezada pelo fato de ser mulher. Quando tive complicações durante a gestação [...] minha chefia [mulher] disse que eu ali não tinha nenhum privilégio e que gestação não era doença.

Isto posto, pressupõe-se que para compreender as dimensões e esferas do cotidiano atravessadas pelas violências, que se expressam e se intercruzam, os marcadores sociais da diferença devem ser estudados e considerados para construção tanto de ações micropolíticas (que atravessam o dia a dia da vida doméstica, as relações afetivas, os processos de trabalho e as ações de cuidado de si, por exemplo) quanto para a produção de macropolíticas públicas que possam efetivamente transformar as relações instituídas socialmente, com base em princípios da afirmação das diferenças, da igualdade de direitos e da justiça social. Uma vez que

As violências cercam a vida de todas as mulheres em todos os espaços, às vezes de forma muito sutil. Mesmo em espaços de movimentos sociais, de partidos que lutam pela igualdade [...]. Ser mulher, muitas vezes, é sinônimo de ser abusada. Tantas formas, tão doídas. [...]. Ser mulher é encarar de frente sofrimento por vários lados.

Desse modo, torna-se necessário que os discursos e as perspectivas progressistas e da saúde coletiva incluam em suas análises e proposições apontamentos e possibilidades que o conceito da interseccionalidade traz enquanto ferramenta sofisticada e potente para análise crítica do modo cada vez mais complexo como as opressões se apresentam na vida cotidiana e nas relações de diferentes grupos minoritários e invisibilizados no Brasil14, como estratégia para produzir uma política dialógica entre os diferentes atores sociais inseridos nesses contextos, em conformidade com a compreensão sobre as intersecções ${ }^{18} \mathrm{e}$ os marcadores da diferença existentes ${ }^{15}$.

Tendo em vista o contexto específico deste estudo, identifica-se que os serviços de saúde, enquanto espaço público de pertencimento, bem como lócus expressivo dos processos cotidianos de trabalho, de formação e de militância, constituem-se como uma zona comum de existência que reproduz e perpetua as violências que deveriam combater.

As relações desiguais de poder baseadas em classes sociais, gênero e raça/etnia, somadas a cenas cotidianas de discriminação e invisibilidade de pautas e demandas das mulheres, implicam a constituição do campo da saúde como um espaço potencial que reproduz os inúmeros desafios de gênero a serem enfrentados pelas mulheres tanto como profissionais quanto como usuárias da rede de apoio e assistência em saúde, com um prejuízo ainda maior para as mulheres negras.

O compromisso com o processo de fortalecimento de si e sua consequente ruptura com os ciclos da violência também se caracterizam em nossa sociedade como funções da mulher, premissa que internalizamos, enquanto grupo. A narrativa abaixo descrita expressa essa função a partir do entendimento da importância de 'ser durona', embora pontue os desafios implicados no processo de ruptura com relações de dominação, tendo em vista o medo e a insegurança produzidos pelas violências que, uma vez percebidas e enfrentadas, produz condições possíveis de emancipação:

Quando se nasce mulher, você precisa ser durona desde o primeiro dia. Mas, de todos os tipos de violência que já sofri, a pior pra mim é a psicológica, porque ela te enclausura em medo e insegurança. Quando você consegue romper esse domínio, consegue superar as demais.

Joice Berth, em seu livro 'Empoderamento'19(18), explicita que o processo de empoderamento, de 'dar poder'/potência requer um aprofundamento das dimensões envolvidas em sua construção, isto é, compreender 'quem dá poder e de que tipo de poder estamos falando'.

Com base nisso, sujeitos e grupos imersos em realidades opressivas são, muitas vezes, 
impedidos de ter e/ou construir uma percepção clara de si enquanto oprimidos e parte de um grupo igualmente oprimido. A fim de não inverter a lógica, ou seja, retirar o poder de um (opressor) para dar a outro (oprimido), mas, sim, subvertê-la, é preciso pensar caminhos para reconstrução das bases sociopolíticas e "enfrentamento da opressão para eliminação da situação injusta e equalização de existências em sociedade"19(23). Assim, é importante reconhecer as forças e condições sistêmicas que nos oprimem enquanto mulheres em suas inserções singulares e, então, atuar na mudança das relações de saber-poder existentes, em um processo de emancipação individual e coletiva.

Tendo em vista as narrativas apresentadas, assim como a análise desenvolvida a partir das percepções e experiências relacionadas a violências de gênero, entende-se que a construção de estratégias de resistência para o enfrentamento das opressões e o fortalecimento dos processos femininos vitais - processos que são necessários não apenas para a sobrevida, mas para a manutenção e a qualificação da vida das mulheres - configuram um dos pilares fundamentais para a transformação da sociedade de modo geral e da vida das mulheres, em específico.

Este estudo buscou identificar se existem essas produções no campo da saúde coletiva e/ou nas narrativas analisadas e, neste caso, lançar luz ao modo como essas produções têm se constituído. $\mathrm{O}$ processo de escuta e trocas dialógicas é apontado como imprescindível para o adequado acolhimento de mulheres vítimas de situações e experiências violentas.

A força de algumas mulheres me ajudou e sair dessa história, que muito me fez sofrer até que resolvi aceitar que vivia um relacionamento abusivo [...].

A inexistência de processos de troca e partilha como esses contribui para a intensificação do isolamento e da sensação de impotência diante da gravidade das violações. "Vivência muito difícil, com poucas possibilidades de partilhar. Me sentia culpada pelo julgamento de terceiros e me adoeceu muito".

A histórica culpabilização das mulheres enquanto vítimas e a sua responsabilização, para que sejam capazes de romper com o ciclo da violência, expõe e denuncia a situação abusiva à qual estamos submetidas, pois saber-se vítima é uma condição que em muito vulnerabiliza a mulher. Visibilizar em ato e narrar essa condição para outras pessoas é um esforço ainda maior e de intenso sofrimento, do qual as mulheres não têm se esquivado.

Os espaços públicos, em especial, os de assistência em saúde, também podem atuar por meio de abordagens inadequadas e que não favorecem a ruptura do ciclo de violência. Nesse sentido, essas práticas constituem violência institucional e contribuem para o aprofundamento da dificuldade das mulheres de relatarem os abusos sofridos e denunciarem seus agressores.

Fatores estruturais relativos ao espaço físico das unidades de atendimento, tais como sala de atendimento pequena e ausência de privacidade; ou à dinâmica dos atendimentos, com pouco tempo disponível para acolhimento humanizado, atuam como limitantes e desfavoráveis para a efetividade e integralidade do cuidado ${ }^{25}$, considerando que um dos pontos de apoio utilizados por mulheres quando vítimas de violências são os serviços de assistência à saúde.

As emoções causadas pelas situações de violência, muitas vezes vividas pelas próprias profissionais em suas vidas pessoais, são consideradas, no estudo de Hasse e Vieira ${ }^{26}$, como possíveis fatores que podem dificultar esse processo de reflexão, acolhimento, atendimento e encaminhamento adequado.

A violência muitas vezes pode aparecer nas pequenas ações e relações cotidianas, o que às vezes não nos faz perceber que estamos sofrendo violência, ainda mais por não compartilharmos as experiências. Muitas vezes, também, a violência é reproduzida por outras mulheres pelo forte machismo em nossa cultura. 
Processos de acolhimento e suporte representados por acompanhamento terapêutico são mais um dos recursos necessários para que as mulheres possam identificar e desnaturalizar as violências em seus cotidianos, para o resgate de sua saúde mental, para fortalecer a autoestima, buscar novas possibilidades de emancipação social, financeira e emocional, bem como para retomar seu protagonismo social e político, para iniciar a ruptura do ciclo de violência.

[...] Após psicoterapia, estou conseguindo superar e não aceitar mais nenhum tipo de ofensa ou assédio moral pautados na minha condição de mulher.

Fui vítima de violência sexual na infância. Marcou minha vida profundamente em diversos aspectos. Depois de adulta, percebi o tanto que isso me afetou e faço terapia desde então [...].

Salienta-se, porém, que o suporte terapêutico em saúde mental ainda figura como recurso privilegiado e, portanto, pouco acessível a muitas mulheres, sobretudo negras e pobres. A cultura da medicalização da vida perpassa os processos de saúde-doença, incluindo aqui o âmbito de desenvolvimento das violências ${ }^{9,25}$.

No Brasil, numa esfera pública e política, o combate às violências centraliza-se, principalmente, na lógica pouco resolutiva do punitivismo, enquanto, em âmbito privado e doméstico, a responsabilidade pela interrupção do ciclo apresenta-se como função da mulher, que, para suportar os processos de vulnerabilização e agressividade, em muitos casos, faz uso contínuo de medicações ${ }^{4}$.

Para que os processos de escuta e trocas se efetivem, sendo capazes de produzir empatia e práticas centradas no cuidado emancipatório-relacional, é importante a visibilidade e a construção de espaços individuais e coletivos em que se possibilite que sejamos ouvidas; nos quais possamos nos sentir seguras para refletir sobre nosso percurso e trajetória, retomar vivências anteriores e presentes de sofrimentos e abusos, sem que sejamos responsabilizadas e culpabilizadas no processo.

É essencial, portanto, que esses espaços (privados/públicos, sociais/institucionais, afetivos/ profissionais, relacionais/acadêmicos), por um lado, instrumentalizem as mulheres a partir da discussão e do delineamento das opressões do mundo moderno, seus desdobramentos teórico-práticos na vida cotidiana e nas instituições e estruturas societárias, e, por outro, ultrapasse as estratégias instrumentalizantes, que operam sobretudo no plano das consciências, incluindo novas modalidades éticas, estéticas e sensíveis de cuidado para a criação de novos mundos possíveis, ativando planos comuns de criação coletiva e de forças ativas.

No que se refere ao processo de instrumentalização, podem-se incluir ações de atenção, formação, educação permanente, gestão e controle social fomentadas por meio do estudo e da aplicação das teorias feministas enquanto produtoras de análise crítica e fortalecimento para produzir enfrentamentos e transformações na sociedade, bem como o aprofundamento daquilo que se compreende por processos de empoderamento enquanto ferramenta de emancipação, visto que, na organização social moderna e tecnológica, seu sentido está sendo esvaziado, devido ao uso superficial, pautado no conceito de marketing para consumo e estética dos $\operatorname{corpos}^{19}$.

[...] Só passei a entender as situações que vivi como violência já na vida adulta, depois de estudar sobre o tema e começar a desnaturalizar tais situações.

[...] Ao término da graduação, voltei a morar com meus pais e nessa época já havia conhecido o feminismo e compreendido que os motivos para as violências cometidas pelo meu pai não eram consequência de álcool e transtorno mental. Passei a enfrentá-lo repetidas vezes quando gritava ou agredia minha mãe.

Quanto há a ativação da potência coletiva de criação de outros mundos possíveis, incluem-se iniciativas inventivas e instituintes 
de fomento de redes colaborativas, espaços convivenciais de experimentações múltiplas ou, dito de outro modo, a criação de zonas comuns existenciais de ruptura com os ciclos de violência:

[...] A participação em movimentos e espaços coletivos me ajudaram a ser dona de mim mesma e ser protagonista. Sou mais forte e feliz. Enfrento as adversidades com muita força e luz.

Nessa direção, destaca-se a proposição de tensionamentos e enfrentamentos materializados pela criação da própria Coletiva Adelaides no campo da saúde coletiva, a fim de pautar e fortalecer um movimento de pesquisa-luta-intervenção que é protagonizado por mulheres militantes feministas em busca de produzir conhecimento pautado nas epistemologias feministas em uma necessária e vital ruptura com o eurocentrismo e consequente transformação das bases de produção acadêmica e intelectual no Brasil. O fortalecimento do feminismo negro nos espaços de debate sobre os estudos de gênero em saúde é também um desafio que essa pesquisa buscou enfrentar, criando zonas de singularização e de composição com outras correntes feministas, ampliando a pauta da negritude nos modos de pensar o feminismo em saúde.

Neste momento histórico-social, é urgente a produção de resistências e a criação de novos modos de cuidar de todas/todos/todes/todxs nós enquanto seres viventes, pautados na partilha de saberes, na divisão igualitária de responsabilidades, no respeito à cultura dos povos originários e afrodescendentes, no combate às opressões raciais, de gênero, de classe, bem como na defesa do meio ambiente e de todos os seres vivos.

O questionário produzido por esta Coletiva atuou tanto como ferramenta de pesquisa quanto como dispositivo de reflexões e intervenções, conforme explícito nesta narrativa: "Com o questionário me dei por conta que havia sofrido violência sexual, mas que nunca tinha falado sobre isso [...]".
Observa-se, portanto, que as epistemologias feministas negras e as pesquisas coletivas são imprescindíveis para a construção de políticas públicas de enfrentamento às violências alinhadas ao conceito de interseccionalidade e ao próprio fortalecimento do SUS como espaço de defesa da vida das mulheres. Além disso, reforça-se a necessidade da ampliação dos estudos de gênero nos espaços de formação em saúde, no âmbito da organização dos serviços de assistência e da instrumentalização da equipe profissional para a produção de práticas de cuidado atentas aos marcadores sociais da diferença, aos estereótipos de gênero e sexistas.

Identificou-se que as mulheres participantes da pesquisa que tiveram acesso a conhecimentos referentes aos feminismos e discussões relacionadas ao enfrentamento do machismo tornaram-se mais fortalecidas e capacitadas para reconhecerem e se posicionarem contra ações violadoras, condição vital para iniciarem processos de ruptura com os ciclos da violência, tanto no setor sanitário como em sua vida cotidiana.

\section{Considerações finais}

Espera-se com este estudo contribuir para a compreensão das violências de gênero em suas expressões cotidianas que foram naturalizadas institucionalmente nos espaços onde a vida se apresenta e delineia, em um processo produtor de realidades violentas e que se perpetuam na vida das mulheres.

A cartografia foi especialmente cara nesta prática de pesquisa, pois permitiu um duplo movimento de produção de conhecimento: por um lado, uma aproximação com diferentes maneiras de narrar as experiências da violência, marcando posições narrativas singulares (narrativas de cada participante e, também, das pesquisadoras implicadas em uma Coletiva de trabalhadoras feministas). Por outro, foi possível a construção de planos comuns da experiência da violência vivida por mulheres 
que partilham, também, o cotidiano de serem profissionais do cuidado, um plano comum povoado por matrizes de opressão interseccionais, relações, saberes, poderes, discursos e práticas historicamente construídos. Dar passagem a esse plano comum que é cotidianamente tecido na vida dessas mulheres é, também, fortalecer a dimensão interventiva da pesquisa cartográfica e, ao mesmo tempo, fortalecer a dimensão coletiva de enfrentamento da própria violência contra mulheres, por meio da afirmação de uma política da narratividade ${ }^{27}$.

Como limites da pesquisa, aponta-se que a perspectiva do feminismo negro interseccional foi adotada na etapa de análise dos dados, impondo limites que poderiam ter sido transpostos caso essa abordagem já tivesse sido adotada na etapa de coleta de dados (o que permitiria, por exemplo, a construção das questões do formulário direcionadas aos marcadores sociais da diferença, assim como a redefinição das sementes do modelo snowball'21). No entanto, esse processo, mesmo que tardio, proporciona, como sugerido por estudos afrocentrados ${ }^{\mathbf{1 4 , 1 7 , 1 8}}$, que se produzam incômodos e transformações aos feminismos latino-americanos, bem como na análise e crítica à sua histórica passividade teórico-prática com relação ao racismo.

Procurou-se dar passagem ao quão vulnerabilizadas nós mulheres estamos com relação à nossa participação e existência no mundo, mesmo em grupos privilegiados do ponto de vista étnico-racial e econômico, e, mais fortemente, em mulheres negras, submetidas (mas não submissas) às vivências subalternizadoras que atravessam historicamente o corpo negro ${ }^{28}$. No Brasil, constata-se o desamparo na precariedade de políticas públicas que considerem as interseccionalidades e não reproduzam ações de caráter enviesado e insuficientes diante da complexidade da cadeia e do entrelaçamento das opressões que estruturam a sociedade.

O conceito de interseccionalidade proposto no âmbito das epistemologias feministas negras ${ }^{14-19}$ representa, então, um dispositivo necessário e central para produções e enfrentamentos efetivos no combate às diferentes opressões que estruturam e afetam a sociedade, de modo geral, e sobretudo os grupos minoritários, porque viabiliza uma análise sobre condições de vida que se constituem a partir de diferentes marcadores sociais que estabelecem (ou não) acesso ao direito à vida e a uma existência digna. Como foi possível observar por meio das narrativas descritas por diferentes grupos de mulheres e que revelam os complexos intercruzamentos de opressões que se dão justamente devido aos marcadores sociais ${ }^{\mathbf{2 8}}$.

O patriarcado tende a produzir um conjunto de efeitos despotencializadores da vida em suas possibilidades de perseverar na existência, pois se pauta em processos de subjetivação morais e reativos, produzindo a tendência de gerar vidas cafetinadas ${ }^{\mathbf{2 9}}$ por processos de colonização da subjetividade feminina.

Sendo assim, para que exista um combate pela vida, é preciso insurgir tanto na esfera macropolítica quanto nos espaços micropolíticos onde a vida germina. A fim de que nós possamos desenvolver um novo roteiro, no qual a macro e a micropolítica que orientam os afetos e desejos não sejam perpassadas por abusos de poder, ao contrário, estejam articuladas nos campos relacionais de nossa cotidianidade, implicando a construção de um novo corpo, que depende de um trabalho teórico transdisciplinar e uma pragmática clínico-estético-política ${ }^{29}$, alinhados às necessidades urgentes de conhecimento situado nos contextos de vida das mulheres e localizados no mundo, em suas contradições e potências ${ }^{28}$, concomitantemente às lutas por justiça social.

\section{Colaboradoras}

Lima FF (0000-0002-8523-9613)* foi responsável substancialmente pela concepção e o planejamento, pela análise e a interpretação dos dados; contribuiu significativamente para 
a elaboração do rascunho e revisão crítica do conteúdo; participou da aprovação da versão final do manuscrito. Ferigato SH (0000-00017567-7225)*, orientadora desta pesquisa, atuou na concepção e no planejamento, análise e a interpretação dos dados; contribuiu significativamente para a elaboração do rascunho e revisão crítica do conteúdo e participou da aprovação da versão final do manuscrito. Silva CR (0000-0002-7079-8340)* e Oliveira ALO (0000-0001-9537-1979)* contribuíram igualmente para a elaboração do rascunho e revisão crítica do conteúdo, participando também da aprovação da versão final do manuscrito.

\section{Referências}

1. Biroli F. Gênero e Desigualdades: os limites da democracia no Brasil. São Paulo: Boitempo; 2018.

2. Saffioti HIB, Almeida SS. Violência de Gênero: Poder e Impotência. Rio de Janeiro: Revinter; 1995.

3. Saffioti HIB. Violência e Assédio Sexual: Violência de Gênero no Brasil atual. Est. Fem. 1994; 2(esp):443-461.

4. Deeke PL, Boing FA, Oliveira FW, et al. A Dinâmica da Violência Doméstica: uma análise a partir dos discursos da mulher agredida e de seu parceiro. Saúde Soc. 2009; 18(2):248-258.

5. Ritt CF. A violência doméstica contra a mulher: Uma afronta aos direitos humanos, direitos fundamentais e a dignidade humana. In: Anais do $8^{\circ}$ Seminário Internacional Fazendo Gênero: Corpo, Violência e Poder; 2008 nov. 25-28; Florianópolis. Florianópolis: UFSC. p. 01-06.
6. Cerqueira D, Lima RS, Bueno S, et al. Atlas da Violência 2018. Nota Técnica, Relatório de Pesquisa, 18. Brasília, DF: IPEA; Fórum Brasileiro de Segurança Pública; 2018

7. Waiselfisz JJ. Mapa da Violência 2015: homicídio de mulheres no Brasil. Brasília, DF: AllType Assessoria Editorial Ltda; 2015.

8. Cerqueira D, Lima RS, Bueno S, et al. Atlas da Violência 2019. Nota Técnica, Relatório de Pesquisa, 19. Brasília, DF: IPEA; Fórum Brasileiro de Segurança Pública; 2019.

9. Han C. Symptoms of another life: time, possibility, and domestic relations in Chile's credit economy. Cultural Anthropology. 2011; 26(1):7-32.

10. Centro Feminista de Estudo e Assessoria. Lei Maria da Penha: do papel para a vida: Comentários à Lei and Contributor ID). 
11.340/2006 e sua inclusão no ciclo orçamentário. Brasília, DF: CFEMEA; 2009.

11. Nobre TM, Barreira C. Controle social e mediação de conflitos: as delegacias da mulher e a violência doméstica. Soc. 2008; (20):38-163.

12. Escorsim SM. Violência de gênero e saúde coletiva: um debate necessário. Rev. Katálysis. 2014; 17(2):235-241.

13. Freire RC, Rodrigues OS, Ferigato SH, et al. A produção do conhecimento sob a perspectiva de gênero e feminista na Saúde Coletiva - o que nos move e o que estamos buscando. In: XX Encontro Nacional da Rede Feminista Norte e Nordeste de Estudos e Pesquisa sobre Mulher e Relações de Gênero (REDOR): Feminismos, produção de conhecimento e ativismos; 2018 dez 4-7; São Paulo. São Paulo: Secretaria Executiva do Encontro Nacional Participação, Democracia e Políticas Públicas; 2018. p. 1-14.

14. Almeida SL. Racismo Estrutural. São Paulo: Polén; 2019.

15. Akotirene C. Interseccionalidade. São Paulo: Polén; 2019. [acesso em 2021 dez 22]. Disponível em: chrome-extension://efaidnbmnnnibpcajpcglclefindmkaj/ viewer.html?pdfurl=https\%3A\%2F\%2Ffiles.cercomp. ufg.br\%2Fweby\%2Fup\%2F1154\%2Fo\%2FIntersecci onalidade_\%2528Feminismos_Plurais\%2529_-_Carla_Akotirene.pdf\%3F1599239359\&clen=1245914\&ch unk=true.

16. Ferrufino AH, Miranda VL, Morrison R, et al. Transacionalismo, Interseccionalidade Feminista e Método Narrativo: aportes para a pesquisa em Terapia Ocupacional e Ciência Ocupacional. Rev. Interinst. Bras. Ter. Ocup. 2019; 3(1):150-161.

17. Ribeiro D. O que é lugar de fala? Belo Horizonte (MG): Letramento, 2017.

18. Gonzalez L. Por um feminismo afro-latino-americano: ensaios, intervenções e diálogos. Rio de Janeiro: Zahaar; 2020.
19. Berth J. Empoderamento. São Paulo: Polén; 2019.

20. Oliveira CF. Mulheres da Saúde Coletiva: um retrato de quem constrói o campo. Em andamento. [tese]. Campinas: Universidade Estadual de Campinas; [no prelo].

21. Vinuto J. A amostragem de bola de neve em pesquisa qualitativa: um debate aberto. Temáticas. 2014; 22(44):203-220.

22. Paulon SM, Romagnoli RC. Pesquisa-intervenção e cartografia: melindres e meandros metodológicos. Estud. Pesq. Psic. 2010; 10(01):85-102.

23. Ferigato SH, Carvalho SR. Pesquisa qualitativa, cartografia e saúde: conexões. Interface (Botucatu). 2011; 15(38):663-676.

24. Nascimento A. O branqueamento da raça: uma estratégia de genocídio. In: Nascimento A. O genocídio do negro brasileiro. Rio de Janeiro: Paz e Terra; 1978.

25. Souza AAC, Cintra RB. Conflitos éticos e limitações do atendimento médico à mulher vítima de violência de gênero. Rev. Bioét. 2018; 26(1):77-86.

26. Hasse M, Vieira EM. Como os profissionais de saúde atendem mulheres em situação de violência? Uma análise triangulada de dados. Saúde debate. 2014; 38(102):482-493.

27. Passos E, Benevides R. Por uma política de narratividade. In: Passos E, Kastrup V, Escóssia L. Pistas do método da cartografia. Porto Alegre: Sulina; 2009. p. 150-171.

28. Bairros L. Nossos feminismos revisitados. Estud. Femin. 1995; 3(2):458-463.

29. Rolnik S. Esferas da Insurreição - Notas para uma vida não cafetinada. São Paulo: n-1 edições; 2018.

Recebido em 29/08/2020

Aprovado em 03/12/2021

Conflito de interesses: inexistente

Suporte financeiro: não houve 


\section{ERRATA}

No artigo "Percepções e experiências de mulheres atuantes no campo da saúde sobre violências de gênero/Perceptions and experiences of women active in the health field on gender violence”, com número DOI: https://doi.org/10.1590/0103-1104202213205, publicado no periódico Saúde em Debate, 46(132):76-92:

\section{Incluir:}

O Quadro 3 depois do seguinte trecho da página 84:

Foram definidas cinco zonas comuns de existência (quadro 3) nas quais observou-se predominância e persistência da violência nos relatos e experiências, tanto nos espaços de vida quanto no modo como se expressam essas agressões e violações no cotidiano das mulheres e em seus fazeres diários.

Quadro 3. Zonas comuns de violência de gênero

\begin{tabular}{|c|c|c|}
\hline $\begin{array}{l}\text { Zonas comuns de existência e } \\
\text { violências de gênero }\end{array}$ & Descrição & Percepções das mulheres identificadas nas narrativas \\
\hline $\begin{array}{l}\text { Processos de Trabalho e Vida } \\
\text { Profissional }\end{array}$ & $\begin{array}{l}\text { Qualificam-se por meio da compreensão } \\
\text { de como se dá a expressão da violência de } \\
\text { gênero nos espaços de trabalho e exercício } \\
\text { profissional das mulheres participantes. }\end{array}$ & $\begin{array}{l}\text { Em contextos profissionais, comumente, minhas falas e reivindicações eram } \\
\text { 'analisadas' como histeria, assim como de outras colegas mulheres. Os } \\
\text { homens tinham escuta totalmente diferenciada. Fui moralmente agredida por } \\
\text { um supervisor que, ao me posicionar contra uma de suas recomendações, me } \\
\text { disse gritando que eu era insuportável [...] pedi demissão porque ficou emo- } \\
\text { cionalmente insustentável permanecer lá. }\end{array}$ \\
\hline
\end{tabular}

[...] Em meu departamento [...], são constantes os comentários depreciativos em relação às mulheres, especialmente piadas. Minhas solicitações de pautas costumam ser esquecidas ou deixadas por último; preciso me fazer ouvir fortemente, senão sou interrompida e não ouvida. [...] São tantas violências que cresci acreditando que realmente era inferior em vários aspectos. Ainda hoje fico insegura, porém, pela primeira vez, aceitei um cargo de gestão na universidade que foi totalmente desvinculado de meu companheiro. Antes disso, era como se estivesse o tempo inteiro na sombra dele. E temos um combinado: ele só pode dar sugestão ou conselhos sobre minha atuação profissional quando for solicitado.

Processos Educacionais de Pesquisa e Formação
São caracterizados como os processos de formação acadêmica das mulheres participantes.
Recebi comentários de um professor sobre atuar na área cirúrgica e ser mãe, afirmando que não há como ser as duas coisas [...].

[...] durante uma prova de recuperação, um professor aproveitou que a sala estava quase vazia e passou a mão na minha perna, subindo em direção à virilha. Ele só parou porque eu comecei a chorar. Eu denunciei para a secretaria acadêmica, porém, nunca tive devolutiva. Foi falado que eles já haviam orientado a não ficar sozinha com esse professor [...] Escutei de colegas [...] que eu só havia passado na disciplina porque eu havia me envolvido amorosamente com o professor. Acabei deixando a história morrer porque na própria secretaria falaram que não dava em nada as denúncias. 


\section{ERRATA}

\begin{tabular}{|c|c|c|}
\hline $\begin{array}{l}\text { Zonas comuns de existência e } \\
\text { violências de gênero }\end{array}$ & Descrição & Percepções das mulheres identificadas nas narrativas \\
\hline $\begin{array}{l}\text { Espaço Doméstico - pertencer } \\
\text { à casa }\end{array}$ & $\begin{array}{l}\text { Espaço de moradia das mulheres partic- } \\
\text { ipantes no qual se apresentam inúmeros } \\
\text { atos de agressão e violência e que transfor- } \\
\text { mam o sentimento de pertencimento ou de } \\
\text { familiaridade em sentimentos de sofrimen- } \\
\text { to, impotência e/ou insegurança. }\end{array}$ & $\begin{array}{l}\text { [...] o cônjuge tenta controlar, retirar direitos, agressões físicas, manda sair do } \\
\text { próprio apartamento. } \\
\text { Violência moral por parte do ex-marido (separação de corpos), que exigia } \\
\text { atenção integral e era violento com os filhos [...]. }\end{array}$ \\
\hline $\begin{array}{l}\text { Relacionamentos e Relações } \\
\text { Familiares }\end{array}$ & $\begin{array}{l}\text { Vínculos e relações afetivas constituídos } \\
\text { pelas mulheres participantes da pesquisa } \\
\text { ampliada }\end{array}$ & $\begin{array}{l}\text { Meu pai foi meu abusador na infância. Por longos anos. Até hoje é muito difícil } \\
\text { viver com isso. Afeta minha saúde e minha qualidade de vida. Me desperta } \\
\text { ódio, e o fato de ser um tabu só faz piorar [...] depois de anos é que percebi } \\
\text { que também sofri e me livrei de duas situações de tentativa de estupro, } \\
\text { homens que ficaram forçando muito a barra pra transar comigo até chegar ao } \\
\text { ponto de eu ter expulsado e empurrado eles de cima de mim no grito. }\end{array}$ \\
\hline $\begin{array}{l}\text { Espaço Público - ocupar as } \\
\text { ruas }\end{array}$ & $\begin{array}{l}\text { Locais nos quais as mulheres transitam e } \\
\text { ocupam enquanto cidadãs pertencentes } \\
\text { à sociedade e que se manifestam como } \\
\text { espaços de expressão da violência em sua } \\
\text { esfera pública. }\end{array}$ & $\begin{array}{l}\text { [...] Não gosto de andar a pé e sozinha, tenho medo e nojo. } \\
\text { As experiências de violência por ser mulher se dão no cotidiano, através de } \\
\text { microagressões. Isso me incomoda especificamente pela falta de segurança } \\
\text { de andar na rua sozinha, pelos riscos que já corri estando em viagens sozinha } \\
\text { e pelos assédios cotidianos que nos amedrontam e agridem. }\end{array}$ \\
\hline
\end{tabular}

Fonte: elaboração própria. 